\title{
The clinical effect of lumbar puncture in normal pressure hydrocephalus
}

\author{
C WIKKELS $\varnothing$, H ANDERSSON, C BLOMSTRAND, G LINDQVIST
}

From the Department of Neurology and Neurosurgery, Sahlgren Hospital, University of Göteborg, Sweden

SUMmARY Owing to all the difficulties involved in selecting patients with normal pressure hydrocephalus for shunt-operation, a cerebrospinal fluid-tap-test (CSF-TT) is introduced. Psychometric and motor capacities of the patients are measured before and after lumbar puncture and removal of 40-50 ml CSF. Patients fulfilling criteria for normal pressure hydrocephalus were compared to patients with dementia and atrophy shown by computed tomography. Normal pressure hydrocephalus patients showed temporary improvement after lumbar puncture. The extent of the temporary improvement appeared to be well correlated with the improvement after shunt operation. Accordingly, the CSF-TT seems to be of value when selecting those patients who will probably benefit from a shunt operation.

The syndrome of normal pressure hydrocephalus is characterised by gait disturbance, progressive mental deterioration and urinary incontinence. ${ }^{1}$ Particularly noteworthy is the complex gait disturbance with spastic-ataxia, extrapyramidal components, and commonly dyspraxia of gait. ${ }^{2}$ In addition, there is in typical cases mental "slowing up" with lack of spontaneity and reduced vigilance. The diagnosis can be established by pneumoencephalography, ${ }^{3}$ isotope cisternography, ${ }^{4}$ different pressure measurements by infusion manometric tests ${ }^{5-7}$ and computed tomography $(\mathrm{CT})^{8}{ }^{9}$ However, these investigations are sometimes inadequate to establish a correct diagnosis, to differentiate other diseases with ventricular enlargement, and particularly to predict which patients will improve after shunting operations. Such a prediction is difficult to make especially when there is a combination of hydrocephalus and primary atrophy. It has generally been accepted that the best results are achieved in patients with "characteristic findings" in the majority of tests. ${ }^{10-14}$ About $50 \%$ of the patients operated with a shunt will improve, ${ }^{15}$ but the morbidity rate varies between $30-50 \%{ }^{11}$ Accordingly, there is a need for both methods to select patients for shunt operation.

It has been reported that reduction of CSF

Address for reprint requests: Dr C Wikkelsø Department of Neurology, Sahlgren Hospital, University of Göteborg, Sweden.

Received 5 June 1981 and in revised form 9 September 1981 Accepted 26 September 1981 pressure by lumbar puncture caused both subjective and objective temporary improvement in some patients with normal pressure hydrocephalus..$^{10} 1617$ Such patients also improved after CSF-shunting. However, no details have been given about the amount of CSF which was drained or to what degree the CSF pressure was lowered. Furthermore, patients who did not temporarily improve by lumbar puncture were reported to benefit from shunting. ${ }^{10}$

Because of the difficulties involved in selecting the patients who would benefit from a CSF-shunt we have developed a simple complementary test-the CSF-tap-test (CSF-TT). Simple psychometric parameters and motor capacities of the patients before and after lumbar puncture and removal of $40-50 \mathrm{ml}$ CSF were measured. The aim of the study was to find an answer to the following questions: (1) do patients with normal pressure hydrocephalus as a rule improve after draining of CSF? (2) is it possible to predict which patients will improve from a shunt operation among patients fulfilling other criteria for normal pressure hydrocephalus? (3) could the degree of improvement by CSF-TT predict the benefit from a shunt operation?

\section{Material and methods}

Patients Two groups of patients were selected for the study. The first group consisted of all patients investigated for normal pressure hydrocephalus during the last 24 months at the Departments of Neurology and Neurosurgery, Sahlgren Hospital. The second group were 
patients with cerebral atrophy on CT and dementia of different aetiologies. These patients were taken as controls.

All patients were subjected to the following investigations: electroencephalography, CT, lumbar isotopecisternography and routine CSF and blood examinations to exclude inflammatory diseases and metabolic disorders. Patients were diagnosed as having normal pressure hydrozephalus and referred for operation, if they had ventricular enlargement at $C T$ and at least two of the following criteria: (1) a typical clinical picture with gait disturbances, progressive mental deterioration and urinary incontinence, (2) characteristic findings at CT, that is diminished periventricular attenuation, dilated temporal horns and no signs of cortical atrophy, (3) retention of isotope in the lateral ventricles for 24 hours or more and a block of flow over the cerebral hemispheres at isotope cisternography. The patients who were to be operated upon underwent a psychiatric examination, which also included more intensive psychological testing than in the "TT-test battery" described below.

CSF-tap-test (CSF-TT) The CSF-TT was performed during two consecutive days in all patients. The patients were tested psychometrically and the walking pattern was analysed at the same hour both days. On day 2 a lumbar puncture was carried out two hours before the tests, and CSF pressure was measured before and after removing $40-50 \mathrm{ml}$ of CSF with the patient in recumbent position. The psychological tests were chosen to measure the changes in the patient's mental abilities following lumbar puncture so as to cover as broadly as possible those mental changes which could be expected to be influenced by shunt operations. At the same time they were chosen to be easily administered by the neurologist in the neurological department and not be too time-consuming. The following three psychological tests and a walking test (the "TT-test-battery") were used. Approximately half an hour was needed to perform all these tests.

(A) Identical Forms ${ }^{18}$ which measure speed of complex perceptual functions. The test consists of 60 items, each containing a row of six figures. The first figure in every item is identical with one of the others and the patient is asked to find out with which one. The test is given with a time limit of 6 minutes. The number of correct items minus 0.25 points for every wrong answer gives the test score.

(B) Bingley's memory test. ${ }^{19}$ The patient is shown a drawing with 12 common objects which he has to name and memorise for 30 seconds. The number of objects immediately recalled is noted. There are four equivalent forms. The mean of the score of two forms registrated at the examination before lumbar puncture, and the mean of the other two $2 \mathrm{~h}$ after lumbar puncture were calculated.

(C) The reaction time An apparatus with combined light and sound stimuli and with three alternative responses was used. Thirty measures were recorded. In order to avoid single measures with a falsestart the three shortest reaction times were always excluded and the fourth shortest time was used as a base for the comparison.

(D) Walking test In order to obtain a simple quantitative parameter of the gait the number of steps that the patient used for walking $18 \mathrm{~m}$ was counted. This test was performed three times, and the mean value was calculated.

Post-operative investigation The normal pressure hydrocephalus patients were re-investigated approximately 3 months after shunt operation. The evaluation included psychometric tests, walking pattern, electroencephalography and CT. A psychological examination (GL) with the more extensive testing than in the "TT-test battery" again was performed to show the eventual mental changes caused by the shunt operation.

\section{Results}

Thirty-five patients have been investigated with the CSF-TT during the last two years. Twenty-one with the diagnosis normal pressure hydrocephalus and fourteen with dementia due to other encephalopathy. Six of the normal pressure hydrocephalus patients were excluded from the study for the following reasons. One patient improved spontaneously. Therefore there was no need for operation. (Improved at CSF-TT). Two patients had associated polyneuropathy, and did not wish for operation (both showed a slight improvement at CSF-TT). One woman with hydrocephalus secondary to meningeal sarcoidosis improved when corticosteroid therapy was administrated and was not operated. (She at first much improved at CSF-TT, but two months later, after successful treatment with corticosteroids, the CSF-TT was negative. Two patients who received ventriculo-peritoneal shunts after subarachnoidal bleeding and head trauma respectively were excluded from the study due to shunt infection which made the follow up after 3 months invalid. The first patient (improvement at CSF-TT) improved dramatically until the shunt infection. He continued to improve even after the shunt had been removed. The second patient (not improved at CSF-TT) did not change either after shunt or after discharging the infected shunt. Accordingly, the patient was not reoperated. Four of the selected controls were excluded. Three were too ill and could not manage the tests, but showed no other signs of improvement. One had Parkinson's disease and dementia with daily fluctuations in the walking ability.

Fifteen patients with normal pressure hydrocephalus (mean age $64 \mathrm{yr}$, range 57-74) were operated upon by a ventriculo-peritoneal shunt (Denver or Hakim system). In ten patients a probable cause of CSF resorption block was found, while five patients were considered to have idiopathic normal pressure hydrocephalus. Three patients had a history of trauma. Three patients had had a subarachnoid 
hemorrhage and three had previously had a stroke two of whom proved to have been haematomas. The last patient had been the subject of a craniotomy 6 years earlier, for pituitary adenoma.

The control series included ten patients (mean age $59 \mathrm{yr}$, range 38-71). Three of them had a pre-senile dementia due to Alzheimer's disease, stage I and II in two and Pick's disease in one. ${ }^{20}$ Three patients had multi-infarct dementia with signs of generalised arteriosclerosis with a high $(>10)$ ischaemic scale score according to Hachinski. ${ }^{21}$ Two patients were chronic alcoholics and two were demented with a disturbance of both pyramidal and extrapyramidal system.

The results of the CSF-TT are shown in table 1 . Test results in the control group were only slightly different between the two investigations, with a slight tendency for the test score to decline after lumbar puncture. On the contrary the group of normal pressure hydrocephalus patients showed improvement in all tests (fig 1). Average improvement was in test (A) $160 \%$, (B) $65 \%$, (C) $30 \%$ and (D) $11 \%$. The CSF tap test results were different between the two groups of patients with respect to $A$ and $B$ $(p<0.05)$ and $D(p<0.01)$. Test $C$ was not used in all patients, which probably explains why the differences were not statistically significant. Normal pressure hydrocephalus patients generally performed better in the memory test than in test reflecting spatio-perceptual performance (fig 1). Shortening of step length was anticipated in the normal pressure hydrocephalus group. After approximately three months all but two of the normal pressure hydrocephalus patients were re-investigated. Eight patients, including one living abroad who was reported to be strikingly improved, had improved greatly and were now living essentially in the same way as prior to the disease. Some patients complained of persisting but moderate memory difficulties. Three patients had severe complications due to the shunt operation (subdural haematoma, intracerebral haematoma and meningeal infection) which explains their deterioration or lack of improvement. Three patients were unchanged and one patient had deteriorated further.

Correlation between results at CSF-TT and shunt operation for the normal pressure hydrocephalus patients are given in table 2. Improvement/ deterioration in the various tests was defined in tests $A$ and $B$ as an increase/decrease in test score of $25 \%$, in tests $\mathrm{C}$ and $\mathrm{D}$ as an increase/decrease of $5 \%$ (SEM of controls). Seven of those eight patients who improved after shunt operation showed improvement

Table 1 Results of CSF-TT and CSF shunting

\begin{tabular}{|c|c|c|c|c|c|c|c|c|c|c|c|c|c|c|c|c|c|c|c|c|}
\hline & & \multirow{3}{*}{$\begin{array}{l}\text { Age } \\
\text { (yr) }\end{array}$} & \multirow[t]{3}{*}{ Sex } & \multirow{3}{*}{$\begin{array}{l}\text { Aetiology/ } \\
\text { Diagnosis }\end{array}$} & \multicolumn{12}{|c|}{$C S F-T T$ results } & \multicolumn{4}{|c|}{ Final results } \\
\hline & & & & & \multicolumn{3}{|c|}{ Test A } & \multicolumn{3}{|c|}{ Test $B$} & \multicolumn{3}{|c|}{ Test $C$} & \multicolumn{3}{|c|}{ Test $D$} & \multirow[b]{2}{*}{$P$} & \multirow[b]{2}{*}{$\boldsymbol{W}$} & \multirow{2}{*}{\multicolumn{2}{|c|}{ 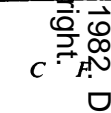 }} \\
\hline & & & & & $\begin{array}{l}\text { Day } \\
I\end{array}$ & $\begin{array}{l}\text { Day } \\
2\end{array}$ & $\begin{array}{l}\text { Month } \\
3\end{array}$ & $\begin{array}{l}\text { Day } \\
I\end{array}$ & $\underset{2}{\text { Day }}$ & $\begin{array}{l}\text { Month } \\
3\end{array}$ & $\begin{array}{l}\text { Day } \\
I\end{array}$ & ${ }_{2}^{\text {Day }}$ & $\begin{array}{l}\text { Month } \\
3\end{array}$ & $\underset{l}{D a v}$ & ${ }_{2}^{D a y}$ & $\underset{2}{\text { Month }}$ & & & & \\
\hline \multirow{25}{*}{ Controls } & 1 & 68 & $\mathbf{F}$ & Idiop. & 0 & $4 \cdot 5$ & $(24 \cdot 5)$ & $2 \cdot 0$ & $4 \cdot 5$ & $(7 \cdot 0)$ & 201 & 116 & $(92)$ & 68 & 58 & (46) & $\uparrow \uparrow$ & $\uparrow \uparrow$ & $\uparrow$ & \\
\hline & 2 & 63 & $\mathbf{F}$ & ," & $17 \cdot 5$ & $27 \cdot 5$ & $(45 \cdot 0)$ & 6.0 & $7 \cdot 5$ & $(6.0)$ & 58 & 49 & (47) & 35 & 30 & (25) & $\uparrow \uparrow$ & $\uparrow$ & $\uparrow$ & \\
\hline & 3 & 74 & $\mathbf{F}$ & SAB & 0 & 0 & (10) & $2 \cdot 5$ & 4 & (5) & - & - & (-) & 56 & 47 & (33) & $\uparrow$ & 4 & $\uparrow$ & \\
\hline & 4 & 63 & $\mathbf{M}$ & ", & $1 \cdot 75$ & 6.0 & (16) & 6.5 & $3 \cdot 0$ & (2) & - & - & (-) & 70 & 49 & (26) & $\uparrow$ & 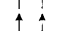 & 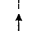 & 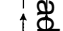 \\
\hline & 5 & 61 & $\mathbf{M}$ & ", & $9 \cdot 0$ & 13.25 & (45) & $1 \cdot 5$ & $3 \cdot 5$ & $(8 \cdot 5)$ & - & - & $(-)$ & 28 & 26 & (23) & $\uparrow$ & 1 & 1 & 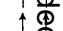 \\
\hline & 6 & 64 & $\mathbf{M}$ & Vasc. & 0 & $7 \cdot 0$ & $(-)$ & $5 \cdot 0$ & $7 \cdot 0$ & $(-)$ & 311 & 111 & $(-)$ & - & - & $(-)$ & $\uparrow$ & $\uparrow$ & $\bar{\uparrow}$ & \\
\hline & 7 & 62 & $\mathbf{M}$ & Traum. & $34 \cdot 75$ & $39 \cdot 75$ & $(41 \cdot 5)$ & $7 \cdot 5$ & $7 \cdot 5$ & $(7 \cdot 5)$ & $\begin{array}{r}311 \\
64\end{array}$ & $\begin{array}{r}11 \\
66\end{array}$ & (63) & $\overline{35}$ & $\overline{32}$ & $(29)$ & 1 & $\uparrow \uparrow$ & $\uparrow$ & \\
\hline & 8 & 66 & $\mathbf{M}$ & ", & $6 \cdot 25$ & $20 \cdot 5$ & $(4 \cdot 0)$ & $5 \cdot 5$ & $7 \cdot 0$ & $(6 \cdot 5)$ & 105 & 97 & (98) & 34 & 30 & (25) & - & $\uparrow$ & $\uparrow$ & \\
\hline & 9 & 60 & $\mathbf{M}$ & " & $22 \cdot 0$ & $36 \cdot 5$ & $(17 \cdot 0)$ & $8 \cdot 5$ & $8 \cdot 5$ & (-) & 57 & 59 & (52) & - & - & (-) & - & 1 & 1 & - \\
\hline & 10 & 61 & $\mathbf{F}$ & Idiop. & $11 \cdot 75$ & $11 \cdot 75$ & $(7 \cdot 75)$ & $4 \cdot 5$ & $5 \cdot 5$ & $(5 \cdot 0)$ & 64 & 65 & (68) & $\overline{54}$ & $\overline{54}$ & $(\overrightarrow{58)})$ & - & $\downarrow$ & - & 一三 \\
\hline & $11^{*}$ & 70 & $\mathbf{M}$ & ", & 1.75 & $12 \cdot 75$ & $(-)$ & $5 \cdot 0$ & $5 \cdot 5$ & (-) & 85 & 72 & (一) & - & - & (30) & $\bar{\downarrow}$ & $\stackrel{\downarrow}{-}$ & - & - \\
\hline & 12 & 66 & $\mathbf{M}$ & ", & $7 \cdot 0$ & $8 \cdot 25$ & $(7 \cdot 5)$ & $3 \cdot 5$ & $3 \cdot 5$ & $(2 \cdot 5)$ & - & - & $(-)$ & 51 & 51 & (52) & \pm & - & - & - \\
\hline & $13^{*}$ & 56 & $\mathbf{F}$ & Vasc. & $8 \cdot 75$ & $11 \cdot 5$ & $(0.75)$ & $2 \cdot 0$ & $2 \cdot 5$ & (-) & 64 & 64 & $(74)$ & 42 & 38 & (32) & $\bar{\downarrow}$ & $\bar{\uparrow}$ & $\bar{\downarrow}$ & $\overline{\overline{5}}$ \\
\hline & $14^{*}$ & 67 & $\mathbf{F}$ & $"$ & 6.0 & $12 \cdot 75$ & $(7 \cdot 25)$ & $7 \cdot 0$ & $7 \cdot 5$ & (-) & 181 & 71 & (75) & 41 & 40 & (35) & $\stackrel{\downarrow}{-}$ & $\uparrow$ & $\downarrow$ & \\
\hline & 15 & 64 & $\mathbf{F}$ & Cran. & 0 & 0 & $(-)$ & 0 & 0 & $(-)$ & - & - & (-) & - & - & $(-)$ & $\downarrow$ & 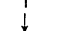 & $\stackrel{\downarrow}{-}$ & 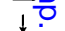 \\
\hline & 1 & 38 & $\mathbf{F}$ & Pick & $40 \cdot 75$ & $33 \cdot 0$ & & 6.0 & $4 \cdot 5$ & & 56 & 60 & & $\overline{26}$ & $\overline{26}$ & & & & & \\
\hline & 2 & 53 & $\mathbf{M}$ & Alz & $17 \cdot 75$ & $23 \cdot 25$ & & 6.0 & $6 \cdot 0$ & & 74 & 64 & & 34 & 34 & & & & & \\
\hline & 3 & 61 & $\mathbf{F}$ & ", & $59 \cdot 25$ & $56 \cdot 75$ & & $5 \cdot 0$ & $6 \cdot 5$ & & - & - & & 32 & 32 & & & & & \\
\hline & 4 & 66 & $\mathbf{F}$ & MID & 0 & 0 & & $4 \cdot 5$ & $3 \cdot 0$ & & - & - & & - & - & & & & & \\
\hline & 5 & 68 & $\mathbf{M}$ & " & $1 \cdot 75$ & $3 \cdot 25$ & & $4 \cdot 0$ & $4 \cdot 5$ & & - & - & & $\overline{61}$ & $\overrightarrow{63}$ & & & & & \\
\hline & 6 & 66 & $\mathbf{M}$ & , & 0 & 0 & & 0.5 & 0 & & - & - & & - & - & & & & & \\
\hline & 7 & 50 & $\mathbf{M}$ & Alc. & $11 \cdot 75$ & $9 \cdot 75$ & & $2 \cdot 0$ & $2 \cdot 5$ & & - & - & & 37 & $\overline{40}$ & & & & & \\
\hline & 8 & 58 & $\mathbf{M}$ & ", & $47 \cdot 75$ & $55 \cdot 5$ & & $7 \cdot 0$ & 6.0 & & 48 & 55 & & - & - & & & & & 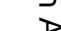 \\
\hline & 9 & 71 & $\mathbf{M}$ & Crypt. & $20 \cdot 5$ & $22 \cdot 5$ & & $5 \cdot 0$ & $4 \cdot 5$ & & - & - & & 52 & 54 & & & & & \\
\hline & 10 & 59 & $\mathbf{M}$ & & $29 \cdot 5$ & $30 \cdot 5$ & & $5 \cdot 0$ & $5 \cdot 5$ & & 53 & 56 & & 56 & 56 & & & & & \\
\hline
\end{tabular}

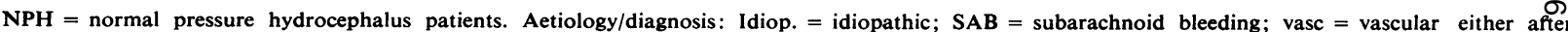

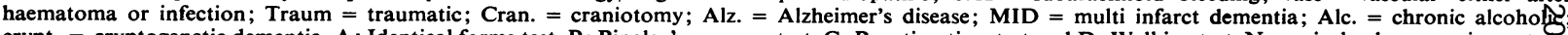

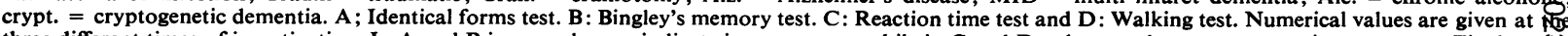

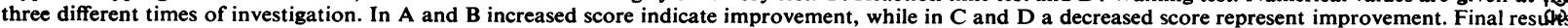

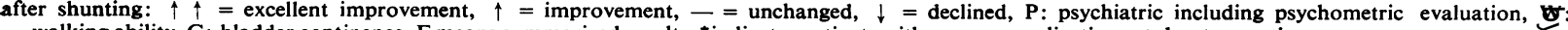
$=$ walking ability, $\mathrm{C}$ : bladder continence. F means summarized results. *indicates patients with severe complications at shunt operation. 

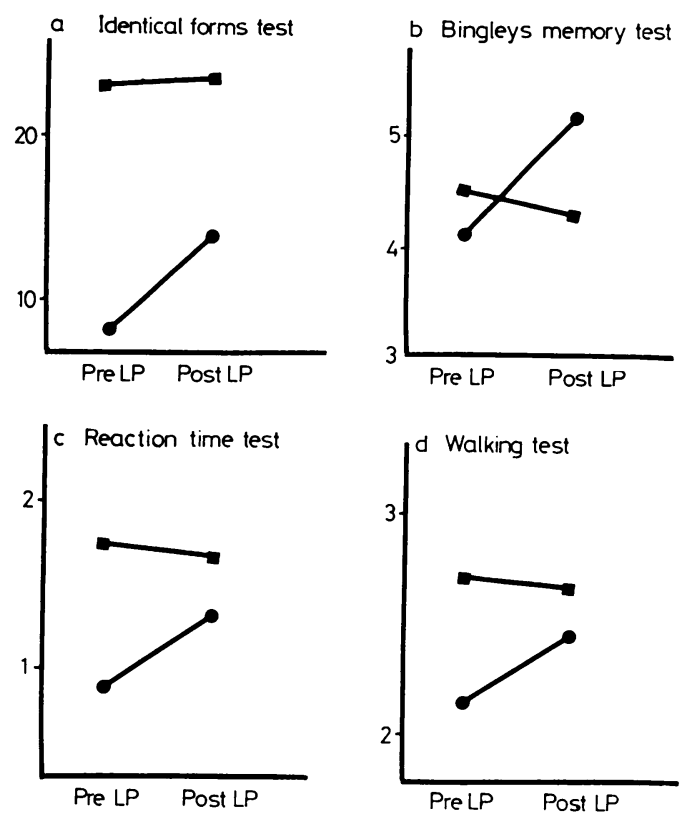

Fig 1 Results of CSF-TT in the normal pressure hydrocephalus group - (15 patients) and in the control group $\square$ (10 patients) before and after lumbar puncture. A: Identical forms test. B: Bingley's memory test, $C$ : Reaction time test and D: Walking test. In tests $A$ and $B$ the numerical average values are given. In $C$ and $D$ reciprocal values. Normal pressure hydrocephalus patients improved in all tests while controls were unchanged.

Table 2 Correlation between CSF-TT requests and clinical changes 3 months after shunt operation

\begin{tabular}{|c|c|c|c|c|c|}
\hline \multicolumn{6}{|l|}{ Effect of Shunt } \\
\hline \multicolumn{6}{|l|}{ Marked } \\
\hline Improvement & & & & & 12 \\
\hline Improvement & & 7 & & & 8 \\
\hline \multirow[t]{3}{*}{ No Improvement } & 1012 & 9 & $11^{*}$ & $14^{*} \quad 13^{*}$ & \\
\hline & & 1 & & 3 & 4 \\
\hline & Impro & emer & ests af & LP at $C S$ & \\
\hline
\end{tabular}

0-4 on the horizontal axis indicates the number of tests (A-D) in the CSF-TT battery in which each subject improved after lumbar puncture. The numbers $1-15$ in Table 2 refer to each normal pressure hydrocephalus patient in table $1 .{ }^{*}$ indicates patients with severe complications at shunt operation

in three or more of the applied tests. The eighth patient (case 7) who improved markedly in continence and walking ability after shunt operation, showed at CSF-TT improvement in the walking ability but no alteration in the psychometric tests. Among those four patients who did not benefit from operation three cases were unchanged in all tests, while the fourth patient improved in test A. Using chi-square
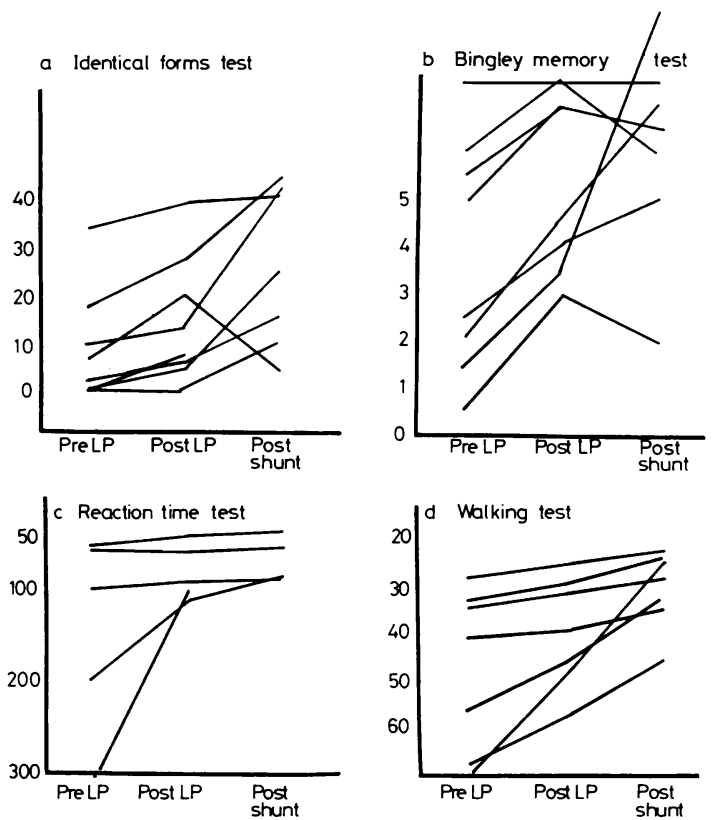

Fig 2 Correlation between results at CSF-TT and the results after shunting in the eight normal pressure hydrocephalus patients who improved after shunt operation. A: Identical forms test. B: Bingley's memory test, C: Reaction time test and D: Walking test. Numerical values are given.

test there was a correlation between improvement at CSF-TT and improvement after shunt operation (level of significance $1 \%$ ). Among the controls slight improvement was seen in five psychometric tests. Only one patient showed slight improvement in two tests. No patients improved in walking ability.

Figure 2 shows the correlation between improvement at CSF-TT and improvement after shunt operation in the eight patients who benefited from shunt operation. With very few exceptions improvement at the CSF-TT was followed by further improvement after shunting. Particularly convincing is the correlation concerning the walking pattern (fig 3). CSF pressure measured with the patients in horizontal position was $15 \mathrm{~cm} \mathrm{H}_{2} \mathrm{O}(\mathrm{SD} \pm 6.9)$ in the controls, and in the normal pressure hydrocephalus $13 \mathrm{~cm} \mathrm{H}_{2} \mathrm{O}(\mathrm{SD} \pm 6 \cdot 4)$ group.

\section{Discussion}

The fundamental mechanical fault responsible for the development of most hydrocephalic states probably is an increase in the hydrodynamic resistance to outflow of CSF from cerebrospinal fluid spaces. It has been proposed that the symptoms and signs of 


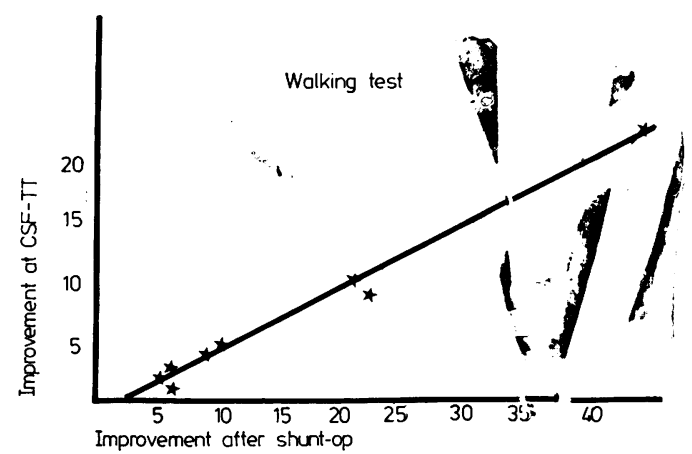

Fig 3 Correlation between walking test imp rovement at CSF-TT (abscissa) and improvement after shunting (ordinate). Improvement is given in number -of steps.

normal pressure hydrocephalus are produced by reduced cerebral blood flow (CBF) 3 scondary to distension of the ventricles. ${ }^{22-24}$ In non nal pressure hydrocephalus CBF has been found to decrease in areas supplied by the anterior cereb al arteries, possibly because the pericallosal arteries a re stretched over the corpus callosum. ${ }^{25} \mathrm{CBF}$ increas : following removal of approximately $30 \mathrm{ml} \mathrm{CSF}$, and the degree of increase has been reported to be correli ted to the improvement after CSF shunting. ${ }^{26}$ T. is has been confirmed by Grubb et al. ${ }^{27}$ However; they also found identical changes in patients wi th cerebral atrophy and this reduces the diagnostic- value of these findings.

Reduced metabolism and neuronal function secondary to the altered CSF hydrodynar miics in the same areas has been proposed as another e prianation for the symptoms and the reduced $\mathrm{CBF}^{25} \mathrm{By}$ withdrawing 40-50 $\mathrm{ml} \mathrm{CSF}$ at CSF-TT the CBF increases, intracranial pressure diminishes and the metabolic function of CSF changes. To est imate the most convenient time for testing patients / psychometrically and in motor function, we obs erved the first patients very closely after lumbar pu ncture. A few patients experienced a slight imf rovement immediately following lumbar puncture, $I$ sut in the majority of patients, the improvement sta ited 30-61) minutes after puncture and lasted for seve ral hours, sometimes as long as 12-24 hours. This o bservatio in might support the idea of a primarily metabclic aetiology.

The fact that only about $50 \%$ of NP $\mathrm{H}$ patis ints improved after shunt operation could pa ttly dep and on initially reversible metabolic/ischae nic cher iges that become irreversible, so that neur al tissues are destroyed as shown in animal experir jents. ${ }^{28} 29$ : The clinical picture, CT and cisternogr $\iota p h y$, hower er, probably would not change even if tr te morphologi zal changes had become irreversible. $R$ emoving 40-50 $\mathrm{ml}$
CSF from the cerebrospinal fluid space as in CSF-TT, creates for a short time a situation identical to the definitive shunt operation and therefore, gives an opportunity to evaluate the degree of reversibility. We found in this study a good correlation between the reaction at CSF-TT and shunt operation. Four patients did not improve at CSF-TT and, subsequently, not to shunting. They did not differ in any other way from the successful patients. All four presented a typical clinical picture, retention of isotope in the lateral ventricles and a block of flow over the cerebral hemispheres, and typical changes at $\mathrm{CT}$.

The psychological test in the "TT-test battery" proved to be reproducible. The two groups could be separated effectively and the clinical improvement, which was remarkable in many patients, was well correlated to the quantitative test measurements. No complications of the CSF-TT were noticed. Since the removal of so much CSF may be hazardous in certain circumstances, there is certainly a need for a thorough neurological investigation to rule out a focal expanding lesion as a cause of hydrocephalus before proceeding to this test.

Summing up we have found (1) patients with normal pressure hydrocephalus as a rule improve after draining of CSF (2) patients who will improve from a shunt operation can be separated from those who will not improve, even if they fulfill all other c.riteriz for normal pressure hydrocephalus (3) the de $; x \geq 3$ of benefit from the shunt operation could be -ritly predicted.

All staff members of the Department of Neurology, ward 23, are thanked for their valuable help. This work was supported by grants from the University of Göteborg and the Medical Society of Göteborg.

\section{References}

${ }^{1}$ Hakim S, Adams RD. The special clinical problem of symtomatic hydrocephalus with normal cerebrospinal fluid pressure. Observations on cerebrospinal fluid Hydrodynamics. J Neurol Sci 1965;2: 307-27.

${ }^{2}$ Messert B, Baker NH. Syndrome of progressive spastic ataxia and apraxia associated with occult hydrocephalus, Neurology (Minneap) 1966;16:44052.

${ }^{3}$ Le May M, New PFJ. Pneumoencephalography and isotope cisternography in the diagnosis of occult normal pressure hydrocephalus. Radiology 1970;96: 347-58.

${ }^{4}$ Benson DF, Le May M, Patten PH, Rubens AB. Diagnosis of normal-pressure hydrocephalus. $N$ Engl J Med 1970;283:609-15.

5 Andersson $\mathbf{H}$, Löfgren $\mathbf{J}$. Hydrodynamic evaluation of shunt performance in hydrocephalus. Hydro- 
cephalus and Spina Bifida. 1968, suppl. 16:30-4.

${ }^{6}$ Katzman R, Hussey F. A simple constant-infusion manometric test for measurement of CSF absorption, I Rationale and method. Neurology (Minneap) 1970; $20: 534-44$.

${ }^{7}$ Ekstedt J, CSF hydrodynamic studies in man. Method of constant pressure CSF infusion. J Neurol Neurosurg Psychiatry 1977;40:105-19.

${ }^{8}$ Gado MH, Coleman RE, Lee KS. Correlation between computerized transaxial tomography and radionuclide cisternography in dementia. Neurology (Minneap) 1976;26:555-60.

${ }^{9}$ Le May M, Hochberg FH. Ventricular differences between hydrostatic hydrocephalus and hydrocephalus ex vacuo by computed tomography. Neuroradiology 1979;17:191-5.

${ }^{10}$ Wood JH, Bartlet D, James AE, Udvarhelyi GB. Normal pressure hydrocephalus: Diagnosis and patient selection for shunt surgery. Neurology (Minneap) 1974;24:517-25.

${ }^{11}$ Greenberg JO, Shenkin HA, Adam R. Idiopathic normal pressure hydrocephalus-a report of 73 patients. J Neurol Neurosurg Psychiatry 1977;40:33641.

${ }^{12}$ Magneas B. Communicating hydrocephalus in adults. Neurology (Minneap) 1978;28:478-84.

${ }^{13}$ Hughes CP, Siegel BA, Coxe WS, et al. Adult idiopathic communicating hydrocephalus with and without shunting. J Neurol Neurosurg Psychiatry 1978;41: 961-71.

${ }^{14}$ Trans JTJ. Differentiation of normal pressure hydrocephalus and cerebral atrophy by computed tomography and spinal infusion test. $J$ Neurol 1979;222: 109-18.

${ }^{15}$ Katzman R. Normal pressure hydrocephalus. In: Wells CE, ed. Dementia. Philadelphia: Davis, 1977.

${ }^{16}$ Adams RD, Fisher CM, Hakim S, Ojemann RG, Sweet WH. Symptomatic occult hydrocephalus with "normal" cerebrospinal-fluid pressure. A treatable syndrome $N$ Engl J Med 1965;273:117-26.

${ }^{17}$ Welch K. Physiology of hydrocephalus. In: Advances in Neurology. Vol. 13, Friedlander WJ, ed. New York: Raven Press, 1975.
18 Thurstone LL. Primary mental abilities. Chicago: The University of Chicago Press, 1943:40-41.

${ }^{19}$ Bingley T. Mental symptoms in temporal lobe epilepsy and temporal lobe gliomas. With special reference to laterality of lesion and the relationship between handedness and brainedness. Acta Psych Neurol 1958, Suppl. 120,33:1-143.

${ }^{20}$ Sjögren $\mathrm{T}$, Sjögren $\mathrm{H}$, Lindgren $\AA \mathrm{GH}$. Morbus Alzheimer and Morbus Pick. Acta Psychiat Neurol Scand 1952, Suppl. 82. 69-115

${ }^{21}$ Hachinski VC, Iliff LD, Zilhka E, et al. Cerebral blood flow in dementia. Arch Neurol 1975;32:632-7.

22 Greitz TVB. Effect of brain distension on cerebral circulation. Lancet 1969;1:863-5.

${ }^{23}$ Greitz TVB, Grepe AOL, Kalmir MSF, et al. Pre-and postoperative evaluation of cerebral blood flow in low-pressure hydrocephalus. J Neurosurg 1969;31: 644-51.

${ }^{24}$ Salmon JH, Timperman AL. Effect of intracranial hypotension on cerebral blood flow. $J$ Neurol Neurosurg Psychiatry $1971 ; 34: 687-92$.

${ }^{25}$ Ingvar D, Schwarts MS. The cerebral blood flow in low pressure hydrocephalus. In: Intracranial pressure II, Lundberg N, Pontén U, Brock M, eds. New York: Springer Verlag, 1975:153-6.

${ }^{26}$ Mathew NT, Meyer JS, Hartmann A, Ott EO. Abnormal cerebrospinal fluid-blood flow dynamics. Implications in diagnosis, treatment and prognosis in normal pressure hydrocephalus. Arch Neurol 1975; $32: 657-64$

${ }^{27}$ Grubb RL, Raichle ME, Gado MH, Eichling JO, Huges CP. Cerebral blood flow, oxygen utilization and blood volume in dementia. Neurolog 1977;27: 905-10.

${ }^{28}$ Weller RO, Wisniewski H, Shulman K, Terry RD. Experimental hydrocephalus in young dogs-histological and ultrastructural study of the brain tissue damage. J Neuropath Exp Neurol 1971;30:613-26.

${ }^{29}$ Miyagami M, Nakamura S, Murakami T, Koga N, Moriyasu N. Electron microscopic study of ventricular wall and choroid plexus in experimentally induced hydrocephalic dogs. Neurol Med Chir (Tokyo) 1976;16 (Pt 1): 15-21. 